\title{
EDITORIAL
}

\section{Women, Environment and the Emerging Transformation of Society}

\author{
C.M. Namafe*, I.A. Nyambe** and P.C. Manchishi** \\ *University of Zambia School of Education, Department of Language and Social Sciences Education, \\ P.O. Box 32379, Lusaka, Zambia
}

**University of Zambia Directorate of Research and Graduate Studies (DRGS), P.O. Box 32379, Lusaka, Zambia

A seminal publication befitting this Directorate of Research and Graduate Studies (DRGS) is that by Carolyn Merchant (1980) ${ }^{1}$ whose book is entitled The Death of Nature: Women, Ecology and the Scientific Revolution. In a manner which set a basis for future developments across the world, Merchant stated that women and the environment (or nature) have an age-old association, an affiliation that has persisted throughout culture, language and history. Their ancient interconnections have been dramatised by the simultaneity of two recent social movements. Just as women are struggling to free themselves from partriachal dominance, environmentalists are equally arguing for the sustainability of society. Women and environment have suffered simultaneous exploitation, pillage and domination throughout centuries in many lands, including Zambia. For this reason, this groundbreaking Journal of Law and Social Sciences (JLSS) of the University of Zambia (UNZA) is set within this context for different justifications set out below.

First, an emerging society in Zambia and beyond needs to be acknowledged as that involving the simultaneous emancipation of women and the environment. Second, this publication is taking place within a global partnership for the United Nations Decade of Education for Sustainable Development, which runs from 2005 - 2014.

In our case, this decade has been made concrete through the publication of this particular Journal, whose selection of articles deliberately addresses the plight of women and the environment in one way or the other. Third, citizens across different countries are, as illustrted by messages of articles featured herein, called upon to understand that a new world of sustainability is emerging, largely powered by two inextricable forces to do with gender and the environmental agenda. In its far-sightedness, the National Policy on Environment (2007) ${ }^{2}$ in Zambia has promulgated that environmental education should be mandatory and taught on a multi-disciplinary basis as well as integrated into ongoing curricula at all levels and on a continuous basis. This is a wake up call for everyone in Zambia and beyond.

The University of Zambia is going in that direction of creating a sustainable intellectual environment as demonstrated and articulated by the 2008 - 2012 University of Zambia Strategic Plan ${ }^{3}$ and subsequently the 2009 UNZA Research and Intellectual Property Rights Policy $^{4}$ and UNZA Postgraduate regulations ${ }^{5}$. The intention by the University to enhance research so as to better inform excellence in teaching and public service is well spelt out in the aforementioned policy documents. The overarching goal of the research enhancement activities is to create local intellectual environment within our campus, strong enough to sustain meaningful intellectual culture. Some of these activities of enhancing intellectual environment on campus to allow the flourishing of academics include creation of various fora for research dissemination. Such research dissemination fora include the establishment of peer-reviewed university journals, annual university symposia, and annual university-wide postgraduate seminars during Postgraduate Seminar weeks. It is to this end that UNZA-JLSS 
is being ushered in as one of the three journals that the university has established for that purpose. Others are the Journal of Agricultural and Biomedical Sciences (JABS) and Journal of Natural and Applied Sciences (JNAS). These came through the realisation ${ }^{6}$ by Prof. Imasiku A. Nyambe of the need by postgraduate students to disseminate their research findings in form of scholarly writings and presentations. It is worth noting here that publishing in peerreviewed journals is still the unsurpassed independent way of gauging scholarly contribution. It is a major basis for evaluating universities, consideration of tenure and promotion of academics/faculty in universities world-wide including UNZA. Certainly, all those engaged in scholarly work ought to publish their works not just for promotions, getting employed or passing graduate studies but for the professional obligation of documenting their respective contribution to knowledge and science. Journal publications are not only the basis of new innovations and technology but also serve to stimulate students, multitudes, other scientists and future research and thus assuring advancement of knowledge. We see this as the main reason of ushering in the UNZA-JLSS so that many of our students, academic staff and scholars out there can have an opportunity to publish their scholarly contributions.

We take this opportunity on behalf of the founding UNZA-JLSS Editorial Board as well as the Journal's founding Editorial Advisory Board to make this important declaration that we usher in UNZA-JLSS as a peer-reviewed university journal and we look forward to it serving you all. This Journal is a medium of instructing people who may never have published in a journal before; it is also open to the general public and institutions both in Zambia and abroad to publish their work. As indicated above, at the University of Zambia, postgraduate regulations require all graduate students to publish their research findings in any journal of their choice. In this regard, UNZA students and, indeed, from other universities in Zambia or abroad may find this particular Journal as their best choice. The Journal scope, as detailed in the instructions to authors, is daunting, covering three disciplines namely education, humanities and social sciences, and law. From an editorial point of view, we know that the growth and survival of this Journal will depend on you, the readers, besides the authors, contributing manuscripts to it as well as those of you who will make yourselves available to help with the peer-review process. We, thus, welcome your input to the Journal and you are free to write your opinions/suggestions to the Journal Editorial Board through the Managing Editor, Journal of Law and Social Sciences, University of Zambia, Box 32379, Lusaka, Zambia. If also necessary, to the Director, Directorate of Research and Graduate Studies, University of Zambia, Box 32379, Lusaka, Zambia.

${ }^{1}$ Merchant, C. (1980), The Death of Nature: Women, Ecology and the Scientific Revolution. New York: Harper and Row.

${ }^{2}$ Government of the Republic of Zambia (2007), National Policy on Environment, Ministry of Tourism, Environment and Natural Resources, Lusaka.

${ }^{3}$ UNZA (2007), University of Zambia 2008-2012 Strategic Plan, UNZA, Lusaka.

${ }^{4}$ Directorate of Research and Graduate Studies (June 2009), UNZA Research Policy and Intellectual Property Rights.

${ }^{5}$ Directorate of Research and Graduate Studies (November, 2009), UNZA Postgraduate Regulations.

${ }^{6}$ Nyambe I.A. (December 2010), Unpublished Concept Note on the Establishment of three Journals: A note presented to the Research Board for aproval. 